\author{
Güliz N. Güncü \\ Yağmur D. Yildırım \\ Hasan Güney Yılmaz \\ Pablo Galindo-Moreno \\ Miguel Velasco-Torres \\ Khalid Al-Hezaimi \\ Reema Al-Shawaf \\ Erdem Karabulut \\ Hom-Lay Wang \\ Tolga F. Tözüm
}

\section{Is there a gender difference in ana- tomic features of incisive canal and maxillary environmental bone?}

Authors' affiliations:

Güliz N. Güncü, Yağmur D. Yıldırım, Tolga F.

Tözüm, Department of Periodontology, Faculty of

Dentistry, Hacettepe University, Ankara, Turkey

Hasan Güney Yllmaz, Department of

Periodontology, Faculty of Dentistry, Near East

University, Mersin, Turkey

Pablo Galindo-Moreno, Miguel Velasco-Torres,

Department of Oral Surgery \& Implant Dentistry,

University of Granada, Granada, Spain and

Department of Periodontics \& Oral Medicine,

School of Dentistry, The University of Michigan,

Ann Arbor, MI, USA

Reema Al-Shawaf, Diagnostic Sciences

Department, College of Dentistry, King Saud

University, Riyadh, Saudi Arabia

Khalid Al-Hezaimi, Hom-Lay Wang, Eng.A.B.

Research Chair for Growth Factors and Bone

Regeneration, Division of Periodontics, College of

Dentistry, Riyadh, Saudi Arabia

Erdem Karabulut, Department of Biostatistics,

Faculty of Medicine, Hacettepe University, Ankara,

Turkey

Hom-Lay Wang, Department of Periodontics \&

Oral Medicine, School of Dentistry, The University

of Michigan, Ann Arbor, MI, USA

Corresponding author:

Dr Tolga F. Tözüm

Department of Periodontology

Faculty of Dentistry

Hacettepe University

3rd Floor, Sihhiye, 06100

Ankara

Turkey

Tel.: +90312305 2237

Fax: +90 3123104440

e-mail: ttozum@hacettepe.edu.tr

Date:

Accepted 8 April 2012

To cite this article:

Güncü GN, Yıldırım YD, Yılmaz HG, Galindo-Moreno P,

Velasco-Torres M, Al-Hezaimi K, Al-Shawaf R, Karabulut E,

Wang $\mathrm{H}-\mathrm{L}$, Tözüm TF. Is there a gender difference in

anatomic features of incisive canal and maxillary

environmental bone?

Clin. Oral Impl. Res. 24, 2013, 1023-1026

doi: $10.1111 /$ j.1600-0501.2012.02493.x

Key words: cone beam computed tomography, gender, humans, implant, maxilla, spiral computed tomography

\title{
Abstract
}

Objectives: The effect of gender on anatomic structures and various body systems were illustrated in the literature. The purpose of this study was to identify the influence of gender and tooth loss on incisive canal characteristics and buccal bone dimensions in the anterior maxilla.

Materials and methods: Computed tomographies (CTs) of 417 male and 516 female patients in four dental clinics were included in this study. The diameter and the length of the incisive canal; width and the length of the bone anterior to the canal; palatal bone length, root length, and root width of the central incisor teeth were measured and recorded from CT sections.

Results: Mean incisive canal length was $11.96 \pm 2.73 \mathrm{~mm}$ and $10.39 \pm 2.47 \mathrm{~mm}$ in men and women, respectively, $(P<0.05)$. In men, mean canal diameter was $2.79 \pm 0.94 \mathrm{~mm}$ whereas in women it was $2.43 \pm 0.85 \mathrm{~mm}$ and this difference was statistically significant $(P<0.05)$. Men had significant higher buccal bone dimensions (length and width of the bone anterior to the canal) than women. Absence of teeth in the anterior maxilla decreased incisive canal length and buccal bone dimensions; however, canal diameter remain unchanged.

Conclusions: Present results suggested a gender related differences in anatomic features of incisive canal and surrounding buccal bone. In addition, crestal canal diameter, buccal bone length, and thickness parameters might be different in distinct countries.

Anterior segments of the jaws in maxillary and mandibular locations are often considered as safer areas when compared with posterior jaws during surgeries (Artzi et al. 2000; Jacobs et al. 2007). Incisive canal (IC), located at the midline, posterior to the central incisor teeth, is an important anatomic structure of anterior maxillary area. However, the anatomic characteristics of this area are poorly documented. Hence, it is important to know the anatomic features in this area when performing surgeries (e.g., implant, bone augmentation, apicoectomy). Nasopalatine nerve and terminal branch of the nasopalatine artery pass through this canal (Song et al. 2009). IC has two to four nasopalatine foramina and one incisive foramen.
Innovations in imaging systems and increased usage of preoperative CT evaluation have allowed us to have a more accurate and close look at these anatomic structures and pathologies (Faitaroni et al. 2011; Guncu et al. 2011). Mean incisive canal length obtained from CT studies ranged from 8 to $12 \mathrm{~mm}$ (Mraiwa et al. 2004; Mardinger et al. 2008; Liang et al. 2009; Song et al. 2009; Bornstein et al. 2010). The narrowest canal diameter was $1.1 \mathrm{~mm}$ and the widest was $6.7 \mathrm{~mm}$ (Song et al. 2009). In addition, there are variously defined morphological types of the canal in the literature (Mardinger et al. 2008; Song et al. 2009; Bornstein et al. 2010). According to the presence or absence of teeth in the anterior maxilla, dimensional changes 
of anterior jaw bones and incisive canal were reported (Mardinger et al. 2008; Liang et al. 2009). Liang et al.(2009) examined 60 dentate and 60 edentulous CT scans and found longer canals in dentate group; however, no change in canal diameter. Affect of gender differences on anatomic structures were also reported in Liang's study (2009). According to the results, men had longer and wider canals (Liang et al. 2009). Moreover, Bornstein et al. (2010) reported the influence of gender and dental status on buccal bone dimensions and incisive canal. Kovisto et al. (2011) investigated the proximity of mandibular canal to the teeth apex and the mesial root of the second molar was found closer to the nerve in female patients compared with male patients.

Our group has previously documented the anatomic features of incisive canal and environmental bone in CT scans of human subjects (Tozum et al. 2012). Canal diameter, canal length and shape, width of buccal and palatal bone, root width and the length of bone between apex of anterior tooth, and nasal floor were examined in that study. Results suggested that there were differences in some parameters between men and women. Evaluating all these parameters together in a high numbered population including multicenter may reveal the distinct impact of gender to the features of incisive canal and maxillary environmental bone. On the basis of the results of our previous study and literature, we aimed to identify the influence of tooth loss and gender on canal characteristics and buccal bone dimensions in the anterior maxilla in the second part of our multicenters study.

\section{Materials and methods}

Computed tomographies of 417 male and 516 female patients in four dental clinics: Turkey (171 CTs), Spain (310 CTs), Saudi Arabia (133 CTs), and Cyprus (319 CTs) were included in this study. A total of 725 of patients were dentate and 208 were edentulous. All the measurements were performed by one calibrated examiner (YDY, MVT, RAS, HGY) at each center on axial CT scans, using software programs. Spiral (Siemens AR-SP 40; Siemens, Munich, Germany) and cone beam (Imaging Sciences International, Hatfield, PA, USA) CT scans were used. A detailed research protocol was discussed and agreed before initiation of the study. Measurements were determined on schematic diagrams and detailed start and end points of the measurements were clarified between calibrated investigators. Intra and inter observer agreement for each measurement was in substantial agreement in each center. The selected landmarks; the diameter and the length of the incisive canal (crestal, middle, and apical); width and the length of the bone anterior to the canal; palatal bone length, root length, and root width of the central incisor teeth were measured according to protocol (Mardinger et al. 2008; Bornstein et al. 2010; Tozum et al. 2012). The anatomic variations of the canal were examined on axial sections and classified into four groups (Mardinger et al. 2008): (1) Cylindrical, (2) Banana-like, (3) Hourglasslike, and (4) Funnel-like. Low quality CT images and $\mathrm{CT}^{\prime}$ s of patients with evident nasopalatine pathology were excluded from the study.

\section{Statistical analysis}

All statistical data analysis was performed in one center (Turkey) using SPSS 11.5.0 software for Windows (SPSS, Chicago, IL, USA). Three-way ANCOVA (country, gender, dentate, and three independent variables) were performed to compare data between dentate and edentate as well as male vs. female patients. When the difference was detected, pairwise comparisons were performed using Bonferroni test. If interaction terms were found statistically significant, subgroups analyses were performed using independent samples $t$-test or one-way ANOVA.

Table 1. The differences in examined parameters in male and female subjects in dentate patients

\begin{tabular}{|c|c|c|c|c|}
\hline & & $\begin{array}{l}\text { Men } \\
(n=312) \\
\text { Mean } \pm \text { SD }\end{array}$ & $\begin{array}{l}\text { Women } \\
(n=413) \\
\text { Mean } \pm \text { SD }\end{array}$ & $P$ \\
\hline Age $(\mathrm{mm})$ & & $41.37 \pm 15.80$ & $40.14 \pm 15.58$ & 0.295 \\
\hline Canal length (mm) & & $11.96 \pm 2.73$ & $10.39 \pm 2.47$ & $P<0.0001$ \\
\hline Buccal length $(\mathrm{mm})$ & & $20.56 \pm 3.36$ & $19.52 \pm 3.18$ & $P<0.0001$ \\
\hline Palatal length (mm) & & $11.58 \pm 2.6$ & $10.63 \pm 2.79$ & $P<0.0001$ \\
\hline Root length $(\mathrm{mm})$ & & $13.17 \pm 1.76$ & $12.25 \pm 1.59$ & $P<0.0001$ \\
\hline \multirow{4}{*}{ Canal diameter $(\mathrm{mm})$} & Crestal & $3.22 \pm 1.05$ & $2.67 \pm 0.89$ & $P<0.0001$ \\
\hline & Medial & $2.26 \pm 0.97$ & $1.95 \pm 0.87$ & $P<0.0001$ \\
\hline & Apical & $2.91 \pm 1.40$ & $2.67 \pm 1.40$ & 0.027 \\
\hline & Mean & $2.79 \pm 0.94$ & $2.43 \pm 0.85$ & $P<0.0001$ \\
\hline \multirow{4}{*}{$\begin{array}{l}\text { Bone thickness anterior } \\
\text { to the canal }(\mathrm{mm})\end{array}$} & Crestal & $6.32 \pm 1.13$ & $5.86 \pm 1.28$ & $P<0.0001$ \\
\hline & Medial & $7.22 \pm 1.56$ & $6.40 \pm 1.39$ & $P<0.0001$ \\
\hline & Apical & $9.84 \pm 2.58$ & $8.92 \pm 2.40$ & $P<0.0001$ \\
\hline & Mean & $7.80 \pm 1.37$ & $7.06 \pm 1.37$ & $P<0.0001$ \\
\hline Palatal bone & Crestal & $2.52 \pm 0.85$ & $2.06 \pm 0.81$ & $P<0.0001$ \\
\hline \multirow{3}{*}{ thickness $(\mathrm{mm})$} & Medial & $5.37 \pm 1.35$ & $4.47 \pm 1.24$ & $P<0.0001$ \\
\hline & Apical & $8.24 \pm 2.16$ & $7.00 \pm 2.02$ & $P<0.0001$ \\
\hline & Mean & $5.38 \pm 1.27$ & $4.52 \pm 1.18$ & $P<0.0001$ \\
\hline \multirow{4}{*}{ Root width (mm) } & Crestal & $6.31 \pm 0.63$ & $5.95 \pm 0.66$ & $P<0.0001$ \\
\hline & Medial & $5.14 \pm 0.61$ & $4.88 \pm 0.59$ & $P<0.0001$ \\
\hline & Apical & $2.19 \pm 0.57$ & $1.97 \pm 0.67$ & $P<0.0001$ \\
\hline & Mean & $4.55 \pm 0.44$ & $4.27 \pm 0.42$ & $P<0.0001$ \\
\hline
\end{tabular}

$P<0.05$ is statistically significant.

\section{Results}

No statistically significant difference was detected between the mean age of 312 male and 413 female dentate patients (Table 1). However, incisive canal length and diameter of dentate subjects differed according to gender. Mean values showed that men had longer and wider canals in dentate subjects $(P<0.0001)$. Buccal bone dimensions (length and width of bone anterior to the canal) were significantly different between genders, $(P<0.0001)$ (Table 1). The roots of central incisor teeth of men were thicker than women as well. When these parameters were examined in edentulous subjects similar results were also found (Table 2). Mean age was also similar in edentulous group, as well as dentate patients. Length, width of the canal, and buccal bone thickness were greater in male subjects compared with female subjects $(P=0.001, P=0.025, P=0.001$, respectively) (Table 2).

Edentulous male and female subjects were older than dentate men and women, as expected $(P<0.0001)$. Absence of teeth in the anterior maxilla caused a decrease at incisive canal length and buccal bone dimensions; however, canal diameter was not changed in men $(P<0.0001)$ (Table 3). Similar results were also observed for women (Table 4). Edentulous women had shorter incisive canals $(P=0.004)$. Buccal bone width and length were smaller in edentulous women than dentate women $(P<0.0001)$ In where men had greater values than women 
Table 2. The differences in examined parameters of male and female subjects in edentate patients

\begin{tabular}{|c|c|c|c|c|}
\hline & & $\begin{array}{l}\text { Men } \\
(n=105) \\
\text { Mean } \pm \text { SD }\end{array}$ & $\begin{array}{l}\text { Women } \\
(n=103) \\
\text { Mean } \pm \text { SD }\end{array}$ & $P$ \\
\hline Age $(\mathrm{mm})$ & & $53.18 \pm 12.83$ & $56.18 \pm 13.02$ & 0.095 \\
\hline Canal length $(\mathrm{mm})$ & & $10.70 \pm 2.53$ & $9.62 \pm 2.31$ & 0.001 \\
\hline Buccal length (mm) & & $17.03 \pm 3.78$ & $15.72 \pm 3.46$ & 0.001 \\
\hline Palatal length $(\mathrm{mm})$ & & $11.53 \pm 2.94$ & $10.25 \pm 2.46$ & 0.001 \\
\hline \multirow[t]{4}{*}{ Canal diameter (mm) } & Crestal & $3.17 \pm 1.12$ & $2.88 \pm 0.96$ & 0.048 \\
\hline & Medial & $2.09 \pm 0.93$ & $1.98 \pm 0.83$ & 0.372 \\
\hline & Apical & $2.91 \pm 1.36$ & $2.54 \pm 1.37$ & 0.053 \\
\hline & Mean & $2.76 \pm 1.01$ & $2.47 \pm 0.85$ & 0.025 \\
\hline \multirow{4}{*}{$\begin{array}{l}\text { Bone thickness anterior to } \\
\text { the canal }(\mathrm{mm})\end{array}$} & Crestal & $4.43 \pm 1.62$ & $3.76 \pm 1.57$ & 0.003 \\
\hline & Medial & $6.77 \pm 1.62$ & $6.10 \pm 1.80$ & 0.005 \\
\hline & Apical & $9.08 \pm 2.51$ & $8.43 \pm 2.04$ & 0.041 \\
\hline & Mean & $6.77 \pm 1.50$ & $6.10 \pm 1.40$ & 0.001 \\
\hline \multirow[t]{4}{*}{ Palatal bone thickness $(\mathrm{mm})$} & Crestal & $2.11 \pm 0.80$ & $1.80 \pm 0.59$ & 0.002 \\
\hline & Medial & $4.91 \pm 1.40$ & $4.25 \pm 1.25$ & 0.001 \\
\hline & Apical & $7.11 \pm 2.07$ & $6.53 \pm 1.96$ & 0.044 \\
\hline & Mean & $4.71 \pm 1.25$ & $4.18 \pm 1.16$ & 0.002 \\
\hline
\end{tabular}

$P<0.05$ is statistically significant. hand, crestal buccal bone thickness of both genders in all countries differed according to dentition status $(P<0.05)$.

\section{Discussion}

Effect of gender and presence of teeth on anatomic structures (such as incisive canal at maxillary region, mandibular canal) have been reported in literature (Mraiwa et al. 2004; Mardinger et al. 2008; Liang et al. 2009; Song et al. 2009; Bornstein et al. 2010; Kovisto et al. 2011; Tozum et al. 2012). Our data showed gender and presence of teeth influenced the incisive canal dimensions and bone dimensions anterior to this canal. When dentate subjects were classified based upon gender, men had greater canal and bone dimensions. Edentulous subjects showed the contrast, there is no significant difference between canal diameter of edentulous and dentate women $(P<0.05)$ (Table 4).

In the whole study population, including men and women, cylindrical canal shape was the most prevalent shape, whereas bananalike was the least in both gender. Women have $45.54 \%$ cylindrical, $26.55 \%$ funnel-like, $16.47 \%$ hourglass-like, and $11.44 \%$ bananalike canals. These parameters were $34.77 \%$, $29.02 \%, 21.58 \%$, and $14.63 \%$, respectively, for men. The percentages of canal morphologies of incisive canal in dentate and edentate subjects according to gender were also presented in Table 5.

According to three-way ANCOVA analysis (country, gender, and dentition status) interactions for buccal bone length, crestal canal diameter, and crestal buccal bone thickness was detected $(P=0.001, P=0.017, P=0.005$, respectively). Country and dentition status interaction was found for buccal bone length. Buccal bone length was higher in Arabia in dentate patients than other countries $(P<0.05)$. Buccal bone length in edantate patients in Turkey was found higher than in Spain and Cyprus $(P<0.05)$.

In addition, country and gender interactions were found for crestal canal diameter for women. Crestal canal diameter of women subjects in Cyprus and Spain was higher than other countries.

Interactions were found for all three independent variables (country, gender, and dentition status) for crestal buccal bone thickness. Gender differences were detected in edantate subjects in Spain whereas it was detected in dentate subjects in Arabia and Cyprus. Crestal buccal bone thickness did not differ for gender and dentition in Turkey. On the other
Table 3. Comparative statistical analysis of dentate and edentate male subjects

\begin{tabular}{lllll}
\hline & & $\begin{array}{l}\text { Dentate } \\
(n=312) \\
\text { Mean } \pm \text { SD }\end{array}$ & $\begin{array}{l}\text { Edentate } \\
(n=105) \\
\text { Mean } \pm \text { SD }\end{array}$ & $P$ \\
\hline Age $(\mathrm{mm})$ & $41.37 \pm 15.80$ & $53.18 \pm 12.82$ & $<0.0001$ \\
Canal length $(\mathrm{mm})$ & $11.96 \pm 2.73$ & $10.70 \pm 2.53$ & $<0.0001$ \\
Buccal length $(\mathrm{mm})$ & $20.56 \pm 3.36$ & $17.03 \pm 3.78$ & $<0.0001$ \\
Palatal length $(\mathrm{mm})$ & & $11.53 \pm 2.94$ & 0.876 \\
Canal diameter $(\mathrm{mm})$ & & $3.17 \pm 1.12$ & 0.685 \\
& Crestal & $3.22 \pm 1.05$ & $2.09 \pm 0.93$ & 0.139 \\
& Medial & $2.26 \pm 0.97$ & $2.91 \pm 1.36$ & 0.965 \\
Bone thickness anterior to & Apical & $2.91 \pm 1.40$ & $2.76 \pm 1.01$ & 0.769 \\
the canal (mm) & Mean & $2.79 \pm 0.94$ & $4.43 \pm 1.62$ & $<0.0001$ \\
& Crestal & $6.32 \pm 1.13$ & $6.77 \pm 1.62$ & 0.012 \\
& Medial & $7.22 \pm 1.56$ & $9.08 \pm 2.51$ & 0.01 \\
Palatal bone thickness (mm) & Apical & $9.84 \pm 2.58$ & $6.77 \pm 1.50$ & $<0.0001$ \\
& Mean & $7.80 \pm 1.37$ & $2.11 \pm 0.80$ & $<0.0001$ \\
& Crestal & $2.52 \pm 0.85$ & $4.91 \pm 1.40$ & 0.003 \\
& Medial & $5.37 \pm 1.35$ & $7.11 \pm 2.07$ & $<0.0001$ \\
& Apical & $8.24 \pm 2.16$ & $4.71 \pm 1.25$ & $<0.0001$ \\
\hline$P<0.05$ is statistically significant. Buccal Length: Bone length anterior to the canal. & \\
\hline
\end{tabular}

Table 4. Comparative statistical analysis of dentate and edentate female subjects

\begin{tabular}{|c|c|c|c|c|}
\hline & & $\begin{array}{l}\text { Dentate } \\
(n=413) \\
\text { Mean } \pm \text { SD }\end{array}$ & $\begin{array}{l}\text { Edentate } \\
(n=103) \\
\text { Mean } \pm \text { SD }\end{array}$ & $P$ \\
\hline Age $(\mathrm{mm})$ & & $40.14 \pm 15.58$ & $56.18 \pm 13.02$ & $<0.0001$ \\
\hline Canal length $(\mathrm{mm})$ & & $10.39 \pm 2.47$ & $9.62 \pm 2.31$ & 0.004 \\
\hline Buccal length (mm) & & $19.52 \pm 3.18$ & $15.72 \pm 3.46$ & $<0.0001$ \\
\hline Palatal length $(\mathrm{mm})$ & & $10.63 \pm 2.79$ & $10.25 \pm 2.46$ & 0.200 \\
\hline \multirow[t]{4}{*}{ Canal diameter $(\mathrm{mm})$} & Crestal & $2.67 \pm 0.89$ & $2.88 \pm 0.96$ & 0.033 \\
\hline & Medial & $1.95 \pm 0.87$ & $1.98 \pm 0.83$ & 0.748 \\
\hline & Apical & $2.67 \pm 1.40$ & $2.54 \pm 1.37$ & 0.404 \\
\hline & Mean & $2.43 \pm 0.85$ & $2.47 \pm 0.85$ & 0.689 \\
\hline \multirow{4}{*}{$\begin{array}{l}\text { Bone thickness anterior to } \\
\text { the canal }(\mathrm{mm})\end{array}$} & Crestal & $5.86 \pm 1.28$ & $3.76 \pm 1.57$ & $<0.0001$ \\
\hline & Medial & $6.40 \pm 1.39$ & $6.10 \pm 1.80$ & 0.113 \\
\hline & Apical & $8.92 \pm 2.40$ & $8.43 \pm 2.04$ & 0.058 \\
\hline & Mean & $7.06 \pm 1.37$ & $6.10 \pm 1.40$ & $<0.0001$ \\
\hline \multirow[t]{4}{*}{ Palatal bone thickness (mm) } & Crestal & $2.06 \pm 0.81$ & $1.80 \pm 0.59$ & $<0.0001$ \\
\hline & Medial & $4.47 \pm 1.24$ & $4.25 \pm 1.25$ & 0.110 \\
\hline & Apical & $7.00 \pm 2.02$ & $6.53 \pm 1.96$ & 0.035 \\
\hline & Mean & $4.52 \pm 1.18$ & $4.18 \pm 1.16$ & 0.009 \\
\hline
\end{tabular}

$P<0.05$ is statistically significant. Buccal Length: Bone length anterior to the canal. 
Table 5 . The percentage of canal morphologies of IC in dentate and edentate subjects according to gender

\begin{tabular}{llll}
\hline Canal morphologies & $\begin{array}{l}\text { Women } \\
(\%)\end{array}$ & $\begin{array}{l}\text { Men } \\
(\%)\end{array}$ \\
\hline Cylindrical & Dentate & 46.97 & 34.61 \\
Banana-like & Edentate & 39.80 & 35.23 \\
& Dentate & 11.38 & 10.47 \\
Hourglass-like & Edentate & 11.65 & 16.02 \\
& Dentate & 17.19 & 21.15 \\
& Edentate & 12.62 & 22.85 \\
Funnel-like & Dentate & 24.45 & 28.20 \\
& Edentate & 35.92 & 31.42 \\
\hline
\end{tabular}

same results when gender was considered. This is the first study looked into these interactions with such a large study group (933 patients). Liang et al. (2009) examined only incisive canal length and diameter on 120 CT scans and found greater values in men in accordance with the present results. Bornstein et al. (2010) examined 44 men and 56 women. They measured canal length, canal width, and buccal bone width; and reported statistically higher buccal bone width and canal length values in men (Bornstein et al. 2010). However, conversely to the present study results, they could not detect canal diameter differences between men and women. They suggested that type of the canal had a significant effect on diameter of incisive foramen, but there was no data about classification of canal types according to gender.

In second part of our study, the effect of presence of teeth to the canal characteristics in men and women were examined. When teeth were not present in the anterior maxilla, both incisive canal length and buccal bone dimensions decreased; however, canal diameter did not change with dental status in both genders. Our study correlates well with Liang et al.'s (2009) study; they reported longer canals in dentate patients with no statistical difference noted for the canal diameter. Mardinger et al. (2008) examined canal dimensions on 207 CT scans and reported a decrease in canal length in edentulous patients. Our results are in agreement with their findings. Based upon these findings, Mardinger et al. (2008) suggested that canal diameter enlarged with tooth loss, like maxillary sinus. On the contrary, Liang et al. (2009) study (120 CT) and present study (933 CT) could not support this hypothesis. Hence, more studies in this area are needed.

In the present study, edentulous women and men had shorter incisive canals than dentate ones. In accordance, Song et al. (2009) examined canal length in 56 maxilla with micro CT and reported decreased canal length in edentulous group. Mardinger et al. (2008) detected similar results; buccal bone width and length decreased in edentulous patients. Moreover, Bornstein et al. (2010) evaluated the effect of dental status on buccal bone width and reported that the width of the buccal bone is the highest in cases when both centrals are present vs. one or two missing central incisors. Similar to these results, bone width anterior to the canal was also detected higher in dentate men and women in the current study.

\section{Conclusions}

Our study demonstrates that gender had a significant influence on anatomic features of anterior maxilla and maxillary incisive canal dimensions. Effect of dental status especially on buccal bone dimensions should not be ignored when performing surgery in the anterior maxilla. CT imaging is a valuable tool to determine anatomic structures before any surgeries in this area including implant surgery.

The authors declare that they have no conflicts of interest.

\section{References}

Artzi, Z., Nemcovsky, C.E., Bitlitum, I. \& Segal, P. (2000) Displacement of the incisive foramen in conjunction with implant placement in the anterior maxilla without jeopardizing vitality of nasopalatine nerve and vessels: a novel surgical approach. Clinical Oral Implants Research 11: 505-510.

Bornstein, M.M., Balsiger, R., Sendi, P. \& Von Arx, T. (2010) Morphology of the nasopalatine canal and dental implant surgery: a radiographic analysis of 100 consecutive patients using limited cone-beam computed tomography. Clinical Oral Implants Research 22: 295-301.

Faitaroni, L.A., Bueno, M.R., Carvalhosa, A.A., Mendonca, E.F. \& Estrela, C. (2011) Differential diagnosis of apical periodontitis and nasopalatine duct cyst. Journal of Endodontics 37: 403-410.

Guncu, G.N., Yildirim, Y.D., Wang, H.L. \& Tozum, T.F. (2011) Location of posterior superior alveolar artery and evaluation of maxillary sinus anatomy with computerized tomography: a clinical study. Clinical Oral Implants Research 22: 1164-1167.
Jacobs, R., Lambrichts, I., Liang, X., Martens, W., Mraiwa, N., Adriaensens, P. \& Gelan, J. (2007) Neurovascularization of the anterior jaw bones revisited using high-resolution magnetic resonance imaging. Oral Surgery, Oral Medicine, Oral Pathology, Oral Radiology, and Endodontics 103: 683-693.

Kovisto, T., Ahmad, M. \& Bowles, W.R. (2011) Proximity of the mandibular canal to the tooth apex. Journal of Endodontics 37: 311-315.

Liang, X., Jacobs, R., Martens, W., Hu, Y., Adriaensens, P., Quirynen, M. \& Lambrichts, I. (2009) Macro- and micro-anatomical, histological and computed tomography scan characterization of the nasopalatine canal. Journal of Clinical Periodontology 36: 598-603.

Mardinger, O., Namani-Sadan, N., Chaushu, G. \& Schwartz-Arad, D. (2008) Morphologic changes of the nasopalatine canal related to dental implantation: a radiologic study in different degrees of absorbed maxillae. Journal of Periodontology 79: 1659-1662.
Mraiwa, N., Jacobs, R., Van Cleynenbreugel, J., Sanderink, G., Schutyser, F., Suetens, P., van Steenberghe, D. \& Quirynen, M. (2004) The nasopalatine canal revisited using $2 \mathrm{D}$ and $3 \mathrm{D} \mathrm{CT}$ imaging. Dento maxillo facial Radiology 33: 396402.

Song, W.C., Jo, D.I., Lee, J.Y., Kim, J.N., Hur, M.S., Hu, K.S., Kim, H.J., Shin, C. \& Koh, K.S. (2009) Microanatomy of the incisive canal using threedimensional reconstruction of microCT images: an ex vivo study. Oral Surgery, Oral Medicine, Oral Pathology, Oral Radiology, and Endodontics 108: 583-590.

Tozum, T.F., Guncu, G.N., Yildirim, Y.D., Yilmaz, H.G., Galindo-Moreno, P., Velasco-Torres, M., Al-Hezaimi, K., Al-Sadhan, R., Karabulut, E. \& Wang, H.L. (2012) Evaluation of incisive canal characteristics related to dental implant treatment with computerized tomography: a clinical multicenter study. Journal of Periodontology, 83: $337-343$. 